Abstract

To understand human nature is to understand the plastic process of human development and the diversity it produces. Drawing on the framework of developmental systems theory and the idea of developmental niche construction, we argue that human nature is not embodied in only one input to development, such as the genome, and that it should not be confined to universal or typical human characteristics. Both similarities and certain classes of differences are explained by a human developmental system that reaches well out into the 'environment'. We point to a significant overlap between our account and the 'life history trait cluster' account of Grant Ramsey. We defend the developmental systems account against the accusation that trying to encompass developmental plasticity and human diversity leads to an unmanageably complex account of human nature.

Keywords
developmental systems theory, developmental niche construction, developmental plasticity,
phenotypic plasticity, Grant Ramsey, Susan Oyama

To appear in Why We Disagree about Human Nature, edited by Tim Lewens and Elizabeth Hannon. Oxford \& New York: Oxford University Press, In Press. 


\title{
A Developmental Systems Account of Human Nature
}

\author{
Karola Stotz and Paul Griffiths
}

\subsection{Current State of the Debate}

The characteristics and causes of human nature are one of the oldest and most contested topics of inquiry. A scientifically credible account of human nature must assimilate and integrate findings from the biological, psychological, and social sciences. Contemporary philosophical work on human nature sets out to do this, but it also tries to stay in touch with older ideas about human nature. Almost all authors have accepted the Darwinian challenge and recognized that the human species is not defined by a fixed, inner essence. But despite this rejection of essentialism, many authors remain attached to the idea that human nature is confined to the left-hand side of the dichotomies between nature and nurture, innate and acquired, biology and culture (Machery 2008; Kronfeldner forthcoming). ${ }^{1}$

This attachment reflects the fact that enquiries into human nature start from an everyday ('vernacular') idea of human nature and try to honour some of the intuitions associated with that idea. The vernacular conception of human nature is an expression of an implicit 'folk theory' of biological development, which has at its heart a distinction between traits that come from 'inside' and those imposed from 'outside'. We and our collaborators have

\footnotetext{
${ }^{1}$ But see Downes and Machery (2013) for a collection of different views; Fuentes et al. (2010) for a collection of essays providing an anthropological challenge to a unitary theory of the human; and Lewens (2012a) for an extremely permissive, if not eliminativist, notion of human nature.
} 
conducted empirical research to characterize this folk theory in more detail (Griffiths 2002; Griffiths et al. 2009; Linquist et al. 2011). The folk theory of animal natures is an instance of 'psychological essentialism' (Medin and Ortony 1989; see also Gelman 2003) and the essential, inner nature of an animal is associated with traits that are fixed in development, typical of the species, and teleological - the animal is intended to have this trait. When this folk theory of animal natures is applied to humans, it produces the vernacular idea of human nature. We describe our 'three-factor' model and related psychological research in section 3.2.

The problem with the vernacular idea of human nature is that it confounds three important but essentially independent biological properties. A trait can be fixed without being typical or having a purpose, it can be typical without having a purpose or being fixed, and it can have a purpose without being fixed or typical. This is one reason why so many developmental biologists and psychologists have rejected a simple dichotomy between innate and acquired characteristics (Lehrman 1953; Hinde 1968; Gottlieb 1970; Bateson 1991). The shortcomings of the vernacular idea of human nature are similar to the shortcomings of the pre-scientific concept of heat. Whether an object feels 'hot' depends on three physical quantities that can vary independently of one another - temperature, quantity of heat, and conductivity. Using these three, more precise ideas, we can explain what people are responding to when they say something is hot; but the original idea is not a useful construct with which to do science.

In this chapter, we defend a view of human nature that goes beyond the vernacular idea, in the same way that the physics of heat went beyond the phenomenological notion of things being hot. We argue that such an idea must fulfil several desiderata: it must be explanatory and not merely descriptive; it should make human nature an object of inquiry in the human sciences (all those disciplines that take the human species or some aspect of it as their 
subject, from physiology through psychology and anthropology to sociology); a science of human nature should explain the folk-biological features traditionally aligned with the idea of human nature in a way that makes clear why they won't do as defining features of human nature; and, lastly, our concept of human nature should embrace human diversity, plasticity, and polymorphism, because these are important aspects of the evolutionary design of human beings. We outline these desiderata in more detail in section 3.3.

We will argue that there are two extant theories that meet these requirements: Grant Ramsey's life history trait cluster (LTC) account (Ramsey 2013) and the developmental systems (DS) account of human nature (Griffiths 2011). In section 3.4, we outline the basic similarity between these two, namely, that both are grounded in human developmental biology. Both accounts suggest that to understand human nature is to understand the plastic but not unstructured process of human development.

While we are in agreement with much of Ramsey's account, in section 3.5 we draw attention to some differences between the two accounts. One major difference is that our account focuses more strongly on the human developmental environment as a critical factor in human nature. Drawing on the framework of developmental systems theory and the idea of developmental niche construction, we argue that human nature is not embodied in one input to development, such as the genome. The patterns of similarity and difference amongst human beings are explained by a human developmental system that reaches well out into the 'environment'.

We also emphasize that developmental systems theory creates a dynamical, process perspective on human nature. Human nature is underpinned by a range of mechanisms of extended inheritance, as well as genetic inheritance, and the life course of any individual human being depends upon a matrix of exogenetic developmental factors - the 
developmental niche. The fundamental unit of analysis in our approach is a process-a human life history (Griffiths and Stotz forthcoming).

\subsection{The folk-biological idea of human nature}

Our account of the folk-biological conception of human nature builds on work in cognitive anthropology and child psychology that identified a pattern of essentialistic thinkingpsychological essentialism - about living things across many human cultures and in human children (Atran 1990; Berlin 1992; Medin and Atran 1999; Medin and Atran 2004; Gelman 2003). It gains additional support from psychological research on the 'genetic essentialism framework' by psychologist Ilan Dar-Nimrod and collaborators. Our earlier work with our collaborators constructed a 'three-factor' model of folk-biological thought about animal natures; provided some experimental evidence for this model; and showed that in contemporary English, the idea of 'nature' is expressed by saying things are 'in the DNA' (Griffiths et al. 2009; Linquist et al. 2011). At around the same time, Dar-Nimrod and collaborators set out to study lay understandings of genetic causation, and documented a set of 'genetic essentialist biases' that correspond closely to elements of the three-factor theory of animal natures (Dar-Nimrod and Heine 2011a, 2011b; Dar-Nimrod and Lisandrelli 2012; Dar-Nimrod et al. 2012; Dar-Nimrod et al. 2014; Cheung et al. 2014).

The three-factor model proposes that there is a folk-biological, implicit theory of development in which some but not all characteristics of animals are expressions of a 'nature' inherited from their parents and which makes them the kind of animal that they are- a human, a chimp, or a kangaroo. Phenotypes that stem from this inner nature are expected to have three characteristics: fixity, typicality, and teleology. Fixity means that the phenotype is hard to change by environmental means. Typicality means that the phenotype is found in all 
or most members of the species (or of some natural subset such as a sex or an age group). Teleology means that the phenotype is part of the design of the organism. It is there for a reason, and organisms that lack these features are not how they are meant to be (see section 3.3, point 3 for a naturalistic interpretation of teleology). In Table 3.1 we show how these factors line up with elements of the genetic essentialist framework (GEF).

The GEF suggests that genetic attributions for various traits, conditions, or diseases activate four specific psychological processes, or genetic essentialist biases. The first bias, termed immutability/determinism, is that thinking about genetic attributions leads people to view relevant outcomes as less changeable and predetermined. To the extent that a phenomenon is perceived to be immutable, it will be perceived to be beyond someone's control. Genetic attributions decrease perceptions of control over relevant outcomes (DarNimrod et al. 2012; Parrott and Smith 2014) and limit the perceived capability of other means, such as environmental manipulations or individuals' volition, to modify the outcome (Jayaratne et al. 2009). The second genetic essentialist bias, termed specific etiology, is a tendency to discount additional causal explanations once genetic attributions are made. Hence, genetic attributions increase the likelihood that people will disregard alternative casual attributions for complex phenomenon (Dar-Nimrod and Heine 2011a). Whereas the first two genetic essentialist biases focus on individuals, the third, termed homogeneity/discreteness, concerns groups. Essentialist thinking leads people to focus on the central identifying features that are common to all group members, drawing attention away from in-group differentiating features. This leads people to view individual members of a category as more homogeneous, which may contribute to stereotyping and more prejudiced attitudes toward group members (Dar-Nimrod and Heine 2011a). The final genetic essentialist bias is termed naturalness. Genetic attributions increase the likelihood that a 
relevant outcome is perceived as a natural outcome. It is widely agreed in both philosophy and psychology that viewing an outcome as natural has important normative overtones.

$<$ COMP: INSERT TABLE 3.1 NEAR HERE - see end of document $>$

The vernacular idea of human nature from which so many philosophical analyses start is simply the application of this form of essentialist thinking to humans. It seeks to divide human characteristics into those imposed by the environment and those that stem from an inner nature, and embodies the assumption that the three characteristics of fixity, typicality, and teleology are strongly associated with one another because traits that stem from our inner nature have these three properties and traits imposed by the environment do not.

However, this intuitive picture of biological development is fundamentally mistaken. All phenotypes are produced by a combination of genetic and environmental factors, and in many cases epigenetic factors. The patterns of interaction between these factors are many and varied, and do not conform to two distinct patterns, one of which is characteristic of traits that have been designed by natural selection. Some philosophers have conceded this, but suggested that there is a continuum, with evolved traits clustered at one end. However, in our view the plausibility of this idea comes not from reviewing the evidence, but from the continued influence of the folk-biological picture (Griffiths and Machery 2008; see also Mameli and Bateson 2006, 2011).

\subsection{Desiderata for an account of human nature}

In this section we ask which desiderata a scientifically credible contemporary conception of human nature should seek to fulfil. Kronfeldner and collaborators have distinguished three main epistemic roles for the concept of human nature (Kronfeldner et al. 2014; Kronfeldner forthcoming). The first is a definitional or classificatory role: human nature defines the 
boundary of the human and determines which individuals are members of the human species. The second is a descriptive role: the concept collects the cluster of traits characteristic of the human life form. This can be seen as making human nature an explanandum, something that stands in need of explanation. The second role is therefore complemented by a third role: the concept as an explanans, identifying the underlying mechanisms or factors that explain why humans have this cluster of traits. There is also a fourth, normative role for the concept in answering the question of what a 'typical' or 'proper' human ought to be. While this is one of the most important traditional roles of the concept of human nature, it has few supporters in philosophy of biology (a seminal critique in this field is Hull 1986). Philosophers who still try to use human nature for this normative purpose do not derive their account of human nature from biology (e.g. the neo-Aristotelian accounts reviewed in Glackin 2016). If species had fixed, typical, and teleological natures in the way that folk biology supposes, then human nature could fulfil the first three roles Kronfeldner identifies, and perhaps the fourth. But since there are no such natures, a scientifically credible concept of human nature must be somewhat revisionary. It will give people something of what they originally wanted from a concept of human nature, but not everything.

We believe that a good concept of human nature should fulfil the following desiderata:

1. It should be explanatory and not merely descriptive. One of us has argued elsewhere that a purely descriptive idea of human nature is relatively uncontroversial (Griffiths 2011). After all, there is a range of sciences that deal with humans, and many of these sciences are successful, which implies that one can abstract away from the particularities of individual human lives to discover commonalities. We suggest that in addition a concept of human nature needs to address what causes these commonalities: it needs to fulfil an explanatory role. 
2. This leads to our second desideratum: a useful concept should make human nature an object of inquiry in the human sciences: the sciences that deal with human beings as a kind. For example, physiology tries to understand functional processes in the human body; psychology studies the human mind, its underlying processes, and the behavioural characteristics it produces; sociology investigates the human kind in terms of social relations and institutions; cultural anthropology is the comparative study of these matters; and so forth.

3. A third desideratum concerns the relationship between a new conception of human nature and the existing, vernacular conception. The new conception cannot include as defining conditions of human nature all the features that are associated with the vernacular concept. As we have already mentioned, these are essentially independent biological properties that we should not expect to be tightly associated with each other (Griffiths 2011). But there are important properties that some human phenotypes exhibit, and a concept of human nature should recognize this. For example, the fixity of traits can be explained by canalization (Waddington 1942), and the fact that there are canalized traits should be part of our understanding of human nature. Typicality is not a defining feature of human nature, but the fact that there are some typical features of human beings needs to be encompassed by our understanding of human nature. Teleology is today standardly explained via evolutionary adaptation — some features really are there by evolutionary 'design' and others are not—so our understanding of human nature should recognize that our nature is in part the outcome of evolutionary design. ${ }^{2}$

\footnotetext{
${ }^{2}$ One problematic aspects of the teleological way of thinking is its resistance to counter-evidence. The nonexistence of a so-called essential trait among a large number of members of a population can
} 
4. Finally, contra Edouard Machery (2008), universality is not a desideratum for a concept of human nature (Ramsey 2012, 2013). If the human species is polymorphic, then this is part of the nature of the human species, something we should seek to understand when we study human beings as a kind. Many organisms also exhibit some form of phenotypic plasticity, the evolved ability to respond with different phenotypes to different environments (Gilbert and Epel 2009; Sultan 2015). This too is an important part of the nature of the species in question. In suggesting that the features of human nature must be universal, Machery is responding to a real feature of the vernacular concept of human nature, but one that clashes with what we have learned about biology since Darwin. So our fourth desideratum is that human nature should admit of polymorphism and plasticity.

In summary, then, we propose that a concept of human nature should make human nature something that explains many features of human beings; that it should make human nature an object of enquiry for the human sciences; that it should make room for developmentally fixed and species-typical traits, and for the fact that some traits are the result of evolutionary design; and finally that it should accommodate the fact that humans are diverse and plastic.

Amongst the many accounts of human nature offered by philosophers, two meet these desiderata. The first is Grant Ramsey's life history trait cluster (LTC) account of human nature (Ramsey 2013) and the second is the developmental systems (DS) account of human nature (Stotz 2010; Griffiths 2011). In the next section we explain the similarities and complementarities of these two accounts, and in section 3.5 we turn to the differences between them.

always be explained as the failure of those individuals to realize their proper nature (we thank Tim Lewens for this comment). 


\subsection{LTC and DST: human nature as human development}

So what is the LTC account? Ramsey acknowledges that human beings are diverse, with each individual life history including a different mix of traits. His account focuses on the patterns of co-occurrence between traits in this population of diverse life histories:

Human nature is defined as the pattern of trait clusters within the totality of extant human possible life histories. Thus, if one were to take all of the possible life histories that form the basis for individual nature, and then combine them, one would possess the set of life histories that forms the basis for human nature, since the trait distribution patterns in this set of life histories constitute human nature. (Ramsey 2013: 987)

Two ideas are combined in this proposal, both of which are central to developmental systems theory: first, 'from an evolutionary point of view an animal is the implementation of a lifehistory strategy'; second, 'bringing order to that diversity is not about identifying universal elements, but about finding order in the patterns of similarity and difference' (Griffiths 2011: $325,328)$. In fact, as we now go on to show, the two accounts are remarkably convergent, albeit arriving at their conclusions from very different starting points.

Ramsey identifies two key desiderata for an account of human nature: that it accord both with scientific practice and with intuitive notions of human nature. The first demands its empirical accessibility as a subject to the human sciences, which is in line with our second desideratum. Ramsey also wants his account of human nature to clarify the related concepts of 'innateness and naturalness' (2013: 986). This requirement has something in common with our third desiderata: that a concept of human nature should shed light on the phenomena of typicality, fixity, and teleology. Ramsey's account also embraces developmental plasticity and diversity, and so meets our fourth desideratum. 
There are other similarities between the two accounts. Ramsey eschews any classificatory role for human nature: an organism is human because it is a member of a particular lineage, not because it displays the LTC property clusters. He also eschews a normative role for human nature: his account may illuminate the idea that some traits are 'natural', but it is not intended as an account of how human beings should be. We agree with both of these points.

Ramsey sometimes seems to regard his account as merely descriptive and not explanatory: 'characterizations of features of human nature are merely descriptions of patterns within the collective set of human life histories' (2013: 988). This apparently clashes with our first desideratum, which calls for an explanatory account of human nature. For two reasons, however, we do not see this as a major difference between our accounts. First, Ramsey's life history trait clusters are exactly what our developmental systems account of human nature explains, which makes his account complementary to ours. Second, we believe that Ramsey actually presents an account of how individual traits that make up the trait cluster can be explained by human nature.

Ramsey's account is more than merely descriptive, we think, because it does not simply list features as a description of human nature. The account focuses on the identification of 'antecedent' (A) and 'consequent' (C) traits of life histories that have been found to be associated with each other. Further experiments should then be carried out, Ramsey suggests, to determine if As and Cs are causally related rather than merely correlated. This would amount to an experimental programme to establish constraints on the possible trajectories within life-history space, and hence the beginning of an explanation of human nature, as well as a description.

Ramsey sketches a quasi-formal account of human nature, involving a 'human-nature space'. This is not the state space of human life histories, as in the last paragraph, but a 
theoretical space in which to locate and compare particular trait clusters. It has two dimensions: the 'pervasiveness, $p$, of the antecedent', defined as 'the proportion of life histories that exhibit that trait', and the 'robustness, $r$, of the antecedent-consequent association' (we are unclear if $r$ is simply a correlation, something like the regression of the consequent on the antecedent, or more explicitly a causal measure). One can increase $p$ by choosing a more broadly defined antecedent, but this will typically reduce the robustness of its association with a consequent. Equally, adding more antecedent traits-make it more complex - can increase $r$, but at a cost to $p$. Hence there is a trade-off between $p$ and $r$, or between simplicity and strength (Ramsey 2013: 989-90).

Ramsey argues that one can make sense of both innateness and naturalness in terms of positions within the $p-r$ space. It may be natural, part of human nature, for humans that have property A to also have property $\mathrm{C}$ - for example, being female (A) and menstruating (C). Since human nature is also associated with traits being innate, innateness could be interpreted in various ways in terms of the $p-r$ space. Either the higher the $r$-value, the more innate a trait is; or innateness can be defined as association with both a high $p$-value and a high $r$-value; or, since neither of these two proposed definitions of innateness implies 'not learned', one could restrict the term 'innate' to A-C links that involve no learning. This, Ramsey (2013: 991) admits, might exclude most, if not all, associations, 'since learning is woven into the causal fabric of so much of development'.

Ramsey (2013: 987) notes that an LTC account of human nature may seem 'spectacularly_and perhaps disastrously_permissive' and 'extremely inclusive'. However, Ramsey argues that although LTC is in principle very permissive, in that it includes all trait associations, it does not imply that all these associations are equally interesting. He proposes the $p-r$ space as a way to distinguish the more interesting features of human nature, those most worthy of study in the science of human nature. Insofar as these interesting trait 
associations are the ones that are more 'natural' or 'innate', this seems to us to be another residual influence of the folk-biological conception of human nature. In any case, Ramsey does not need to defend himself against this criticism. As we explain in the next section, the idea that accounts of human nature should not be 'permissive' or 'inclusive' is simply mistaken.

Finally, Ramsey claims that while his account is not normative, it nevertheless has 'moral implications'. Since this account gives us robust insight into the human condition, good and bad, it could guide action via desired or unwanted antecedent-consequent associations (Ramsey 2013: 992). That biology can have moral implications in this straightforward way has often been noticed: 'Starving children stunts their growth and ruins their health and this is one reason not to starve them' (Sterelny and Griffiths 1999: 5).

\subsection{The developmental systems account of human nature}

The developmental systems account describes human nature in a way very similar to Ramsey. Organisms are fundamentally processes (Griffiths and Stotz forthcoming) — life cycles - and heredity is the reconstruction of the life cycle using resources that are passed on by previous generations. Some of these resources are genetic, some epigenetic, and some exogenetic - the last term referring to a 'developmental niche' that contains reliable developmental resources from outside the organisms. ${ }^{3}$ Some exogenetic resources serve to canalize development, and some to modify it and hence enable developmental plasticity.

Developmental systems theorists have long recognized Ramsey's point that a single lineage has many possible developmental trajectories: 'life cycles may have a disjunctive

\footnotetext{
${ }^{3}$ For an account of the unique features of human nature that accords a very substantial role to the developmental niche, see Sterelny $(2012,2003)$.
} 
form, with different individuals having different characteristics. A developmental system can proliferate by producing a range of outcomes on different occasions' (Griffiths and Gray 1994: 296). Descriptive human nature is the 'order in the patterns of similarity and difference' in these human life cycles (Griffiths 2011: 328).

Developmental systems theory explains human nature as the product of the human developmental system, a matrix of genetic, epigenetic, and exogenetic resources within which the developmental process or life cycle unfolds. This system is constructed by earlier human life cycles and by feed-forward effects from the development of the individual itself. Progress in understanding human nature, on this view, is simply progress in the sciences of human development: developmental biology, developmental psychobiology, and developmental psychology (for a brief history of DST and the scientific research traditions from which it emerged, see Griffiths and Tabery 2013).

Ramsey's fear that the LTC account might be criticized as 'spectacularly — and perhaps disastrously_-permissive' echoes the assessment by Kronfeldner and collaborators of the developmental systems account of human nature:

The result is a concept of an all-inclusive human nature that comprises all the resources needed to stabilize the development of the patterns of similarity and difference observable in humankind. Human nature, the thing that explains and defines the human species, is then a genealogically anchored explanatory essence of gigantic proportions, namely the whole developmental system of humankind, including the developmental niche [... this is] a very distant relative of the traditional concept of human nature, since it construes everything involved in and resulting from human development as part of human nature. It is doubtful whether such an all-encompassing concept of human nature is of any concrete use for the sciences, that is, for describing and 
explaining commonalities or explaining differences within humankind or between the human and other species. (Kronfeldner et al. 2014: 649; emphasis added)

This is a non sequitur: the observations made about the DST account do not support the conclusion. In fact, the DST account has a better prospect of 'describing and explaining commonalities or explaining differences' than does the 'traditional concept of human nature', which excludes much of human diversity. If the aim was to pick out some individuals as not human or as less human, then we might need a simple definition of the human, like a CO1 gene barcode, but hopefully no one is trying to do that! If, instead, the aim of studying human nature is to understand what human beings are like and why they are like that, then we see no reason why either the description of human nature or its underlying explanation should be simple. It seems obvious that both will be complex.

Kronfeldner et al. seem to be echoing a common criticism levelled at developmental systems theory: that paying attention to the role of the environment in development and to the plasticity of development will make the study of development scientifically intractable and its results incomprehensibly complex. The same accusation has been levelled against the scientists whose work inspired DST, and the reply is the one those scientists gave'development is complicated' (Bateson 1991: 19). Complex interactions between genetic, epigenetic, and exogenetic factors explain the constraints on developmental trajectories in the state space of possible human life histories that constitute human nature on our view, and on Ramsey's view as we interpret it. ${ }^{4}$ It would be convenient if these could be reduced to a few

\footnotetext{
${ }^{4}$ A difference between Ramsey's account and our own may concern the status of the genome, which DST put on a much more equal footing to the environment than it enjoys on the LTC account: 'If genes were allowed to vary, individual nature would be vacuous since sufficient changes to genes could, say, change an American into an aardvark. By contrast, varying the way that an individual
} 
simple parameters, like the average velocity of molecules in a gas, but it is clear that they cannot. $^{5}$

Developmental systems theorists have repeatedly emphasized that an inclusive definition of the developmental system does not mean that the whole system must be studied at once, any more than the inclusive definition of the proteome precludes studying individual proteinprotein interactions (Griffiths and Gray 2005; Oyama 2000). The concept of the developmental niche, which seems to be of particular concern to Kronfeldner et al., is a construct from empirical research on behavioural development (West and King 1987). It was introduced into DST to give greater structure to the extra-organismic component of the developmental system (Stotz and Allen 2012; Stotz and Griffiths 2016). The developmental niche concept has been used to great effect in such different fields as the development of social behaviour and communication in birds (West and King 1987, 2008), and speciestypical development in general in rats (Alberts 2008). Other research groups have applied DST's view of development and the concept of the developmental niche to investigate aspects of human development (Alberts and Ronca 2012; Gros-Louis et al. 2014; Gros-Louis et al. 2016; Narvaez et al. 2013). None of this research has become mired in an unmanageable sea of complexity because it recognizes that the human life cycle has evolved to make use of a highly specific developmental niche, or that interaction with this niche may induce developmental plasticity.

Developmental systems theory does not make it possible to sum up human nature in a slogan, but it does point clearly to the body of knowledge that constitutes our current best encounters its environmental heterogeneity reveals something about its nature' (Ramsey, Ch. 2 this volume).

${ }^{5}$ This is not to reject research programmes in systems biology that aim at substantial reductions in the complexity of development through identifying systems-level variables. 
understanding of human nature: human developmental biology, developmental psychobiology, and developmental psychology. When those sciences are complete, we will have a complete understanding of human nature. We fail to see the force of the objection 'but that will be very complicated'.

\subsection{A distinctive feature of the DS account: human}

\section{developmental niche construction}

While Ramsey focuses on descriptive property clusters that make up human nature, the developmental systems account focuses on the underlying processes that account for these clusters. Developmental systems theory subscribes to a process account of the organism, and this is reflected in its view of human nature. DST is a process theory because developmental systems are essentially extended in time (Griffiths and Gray 1994, 1997; Griffiths and Stotz forthcoming):

[DST] seeks to explain developmental outcomes as the result of a dynamic process in which some of the interacting factors are products of earlier stages of the process, rather than as the result of the arrangement of pre-existing factors into a static mechanism. Even when factors exist independently of the developmental process, they are drawn into it and made part of a developmental 'system' by the unfolding process. (Griffiths and Stotz forthcoming)

The focus on property clusters makes Ramsey's LTC account look less processual. However, these properties are not merely properties of organisms, but properties of an organism at a time, and the property clusters that constitute human nature are correlations between what happens at one point in a life cycle and what happens at a later point. So Ramsey's account 
actually fits a process view of the organism quite well. Moreover, Ramsey conceives of the series of events that make up an individual human being as a life history, the implementation of an evolved strategy for resource allocation across the lifespan. In our recent work (Griffiths and Stotz forthcoming) we have argued that it is a life-history strategy that constitutes the principle of identity which unites a series of events as a single life cycle, rather than a part of a larger cycle, or a process involving more than one individual.

The main difference between the two accounts is that the DS account has a stronger focus on the role of the environment in constituting human nature. There is an old saying within anthropology that culture is not only part of human nature, but that our nature is culture. Some recent work on human evolution has emphasized the role of selective niche construction: the evolution of the unique characteristics of human psychology and social structure has been substantially driven by the selection pressures created by earlier psychologies and social structures (Laland et al. 2000; Sterelny 2012). Niche construction theory deals with the selective niche, defined by the parameters that determine the relative fitness of competing types in a population. In selective niche construction, earlier generations partly construct the selection pressures that act on future generations. But another aspect of human niche construction is that our development is dependent on a rich developmental niche of interaction with parents and other conspecifics, and with physical and cognitive artefacts from tools to languages. The developmental niche is defined by the parameters needed to ensure the reconstruction of the evolved life cycle. The concept of the developmental niche is designed to integrate and formalize the non-genetic yet heritable factors influencing an organism's development (Stotz 2010, 2014, forthcoming; Griffiths and Stotz 2013).It was first proposed under the name 'ontogenetic niche' by developmental psychobiologists West and King (1987). 
In our current formulation of the concept (Griffiths and Stotz 2013, forthcoming), the developmental system consists of genetic resources, epigenetic resources, and an exogenetic developmental niche, which contains reliably inherited physical, social, ecological, and epistemic resources needed to reconstruct or — in the case of phenotypic plasticity - modify that developmental system. These resources can be actively constructed by the parents (producing the 'parental effects' of quantitative genetics) or by the larger group, coconstructed by parent and offspring, or sourced passively from a stable environment. Wherever they come from, if there exists an evolutionary (historical) explanation for the interaction of the evolved developmental system with the resource, then that resource is part of the system. What evolves by natural selection is a relationship between the system and each resource.

How does the developmental niche influence human development? Human babies are needy. They are born early in comparison to other primates, meaning that for several months postnatally, relative to other primates, human babies share characteristics of foetuses rather than of infants in those other primates (Trevathan 2011). Comparing brain size at birth among primates, humans should be born at 18 months of age. A large part of brain development takes place outside the uterus, allowing for much greater postnatal epi- and exo-genetic influence than for their ape cousins, which makes the early niche fundamental for human development. Over the course of human evolution, as brains became bigger and human infants more immature at birth, human childrearing practices evolved in tandem to ensure the survival of the helpless infant. As bipedalism, hemochorial placenta, large brains, and the need for a greater amount of learning after birth emerged, human evolution intensified parental care: 'Only with intensified parental care in response to greater helplessness of the infant could selection favor the evolution of a large brain in a bipedal animal' (Trevathan 
2011: 33). So the evolution of a more complex and resource-demanding developmental niche has been a key feature of human evolution.

For this reason, it seems to us entirely natural to say that that human nature resides partly in the human developmental environment. We are a species that is particularly strongly influenced by niche construction, both selective niche construction over evolutionary timescales and developmental niche construction over ontogenetic timescales. A concept of nature according to which what is natural must come from the inside is particularly unsuitable for such a species. Imagine trying to determine the real nature of an ant, another powerful niche constructor, by removing the influence of the nest on the developing egg and embryo. The result would be either dead or biologically meaningless; and so it is for humans.

The developmental niche has two fundamental functions. One function is to ensure the stable, reliable development of species-typical traits. So what explains typicality is the developmental systems dynamics within what we may call 'normal' parameters, some of which are provided by pre-existing physical and developmental constraints. The rest are ensured by reliably and stably inherited resources, which include not just the genome but also essential environmental resources that (among other functions) assist in the species-typical expression of the genetic factors. These stable resources also partially explain fixity. In addition, there are developmental mechanisms that buffer against internal (genetic, epigenetic, metabolic) and external perturbations. These are invoked when we talk about canalization.

But one of our desiderata was that human nature needs to embrace and explain human diversity: 'The search for a shared human nature cannot be the search for human universals; it must instead be a way to interpret and make sense of human diversity' (Griffiths 2011: 326). Here the second function of the developmental niche comes in. Beyond ensuring reliable development, the developmental niche also provides input to developmental plasticity. 
Plasticity is often defined in terms of a genotype's ability to produce different phenotypes in response to the environment. It would be more accurate, however, to say that the shape of the norm of reaction is a property of the whole developmental system. So what explains human diversity are differing developmental systems dynamics supported by modifications in the developmental niche. In other words, human diversity results primarily from the interaction between the evolved developmental system and a wide range of environments, including novel environments: 'Bringing order to that diversity is not about identifying universal elements, but about finding order in the patterns of similarity and difference' (Griffiths 2011: 328). Developmental niche construction therefore provides dependability, but also adaptive flexibility, in the provision of necessary developmental resources.

\subsection{Conclusion}

In this chapter we have reiterated our view that human nature is simply human development.

To the extent that we understand human developmental biology, developmental psychobiology, and developmental psychology, we understand human nature. Like Ramsey's LTC account of human nature, this amounts to saying that human nature is a set of constraints on possible human developmental trajectories. Like Ramsey's account, it is not without content because, although it does not identify a set of outcomes that are 'unnatural', it does say that 'you can't get there from here'. This gives our account, like Ramsey's, a very special and positive feature: it is able to embrace human diversity as part of human nature. As we have argued in section 3.2, the objection that our account leads to a very complex picture of human nature is a non sequitur: human nature is complicated.

Our account differs from Ramsey's in a greater stress on the role of the human developmental environment — the developmental niche — in constituting human nature. We 
have argued that this reflects the direction of the human sciences in recent years. If it clashes with a folk-biological intuition that nature must come from 'inside' rather than 'outside', so much the worse for that intuition-we understand human nature better now.

Kronfeldner and colleagues (Kronfeldner et al. 2014; Kronfeldner forthcoming) have proposed a 'pluralistic solution' for the missing consensus in the philosophical literature regarding a concept of human nature. They suggest that 'different scientific fields are in need of different concepts of human nature, each fulfilling an independent epistemic role'. We are sympathetic to this general approach to the analysis of scientific concepts. We ourselves have made a similar suggestion about the concept of the gene: different gene concepts should be understood as 'tools of research, as ways of classifying the experience shaped by experimentalists to meet their specific needs' (Stotz and Griffiths 2008, p. 41; see also Griffiths and Stotz 2013). We do not, however, think that the same argument applies to the concept of human nature. Human nature is less a technical concept applied in the laboratory than a pragmatic, and even normative, tool applied in wider social contexts and with wideranging consequences. This does not mean that different scientific endeavours cannot study different aspect of human nature, but they cannot do this without paying attention to other fields. There have been several attempts to impose a simplistic understanding of human nature, often derived from evolutionary biology, and to marginalize other sciences, such as those that focus on the human developmental environment. As Sandra Mitchell has argued, an 'anything goes' pluralism in science may do more harm than good, while a real 'integrative pluralism' is a useful defense against reductionist imperialism (Mitchell 2003, 2009).

\section{References}

Alberts, J. R. (2008). 'The Nature of Nurturant Niches in Ontogeny.' Philosophical Psychology 21: 295-303. 
Alberts, J. R., and Ronca, A. E. (2012). 'The Experience of Being Born: A Natural Context for Learning to Suckle.' International Journal of Pediatrics e129328: doi:10.1155/2012/129328.

Atran, S. (1990). Cognitive Foundations of Natural History: Towards an Anthropology of Science. Cambridge: Cambridge University Press.

Bateson, P. (1991). ‘Are There Principles of Behavioural Development?' In P. Bateson (ed.), The Development and Integration of Behaviour: Essays in Honour of Robert Hinde, 19-39. Cambridge: Cambridge University Press.

Berlin, B. (1992). Ethnobiological Classification: Principles of Classification of Plants and Animals in Traditional Societies. Princeton, NJ: Princeton University Press.

Cheung, B. Y., Dar-Nimrod, I., and Gonsalkorale, K. (2014). ‘Am I My Genes? Perceived Genetic Etiology, Intrapersonal Processes, and Health.' Social and Personality Psychology Compass 8: 626-37.

Dar-Nimrod, I., and Heine, S. J. (2011a). 'Genetic Essentialism: On the Deceptive Determinism of DNA.' Psychological Bulletin 137: 800-818.

Dar-Nimrod, I., and Heine, S. J. (2011b). 'Some Thoughts on Essence Placeholders, Interactionism, and Heritability: Reply to Haslam (2011) and Turkheimer (2011).' Psychological Bulletin 137: 829-33.

Dar-Nimrod, I., and Lisandrelli, G. (2012). 'It's in My Genes: Causal Attributions and Perceptions of Choice.' Advances in Psychology Research 95: 187-98.

Dar-Nimrod, I., Zuckerman, M., and Duberstein, P. R. (2012). 'The Effects of Learning about One's Own Genetic Susceptibility to Alcoholism: A Randomized Experiment.' Genetics in Medicine 15: 132-8. 
Dar-Nimrod, I., Zuckerman, M., and Duberstein, P. (2014). 'Smoking at the Workplace: Effects of Genetic and Environmental Causal Accounts on Attitudes toward Smoking Employees and Restrictive Policies.' New Genetics and Society 33: 400-412.

Downes, S. M., and Machery, E. (2013). Arguing about Human Nature: Contemporary Debates. New York: Routledge.

Fuentes, A., Marks, J., Ingold, T., and Sussman, R. (2010). 'On Nature and the Human.' American Anthropologist 112: 512-21.

Gelman, S. A. (2003). The Essential Child: Origins of Essentialism in Everyday Thought. New York: Oxford University Press.

Gilbert, S., and Epel, D. (2009). Ecological Developmental Biology: Integrating Epigenetics, Medicine, and Evolution. Sunderland, Mass.: Sinauer Associates.

Glackin, S. N. (2016). 'Three Aristotelian Accounts of Disease and Disability.' Journal of Applied Philosophy 33: 311-26.

Gottlieb, G. (1970). 'Conceptions of Prenatal Behavior.' In L. R Aronson, E. Tobach, D. S. Lehrman, and J. S. Rosenblatt (eds), Development and Evolution of Behavior: Essays in Memory of T. C. Schneirla, 111-37. San Francisco, Calif.: W. H. Freeman.

Griffiths, P. E. (2002). 'What Is Innateness?' The Monist 85: 70-85.

Griffiths, P. E. (2011). 'Our Plastic Nature.' In S. Gissis and E. Jablonka (eds), Transformations of Lamarckism: From Subtle Fluids to Molecular Biology, 319-30. Cambridge, Mass.: MIT Press.

Griffiths, P. E., and Gray, R. D. (1994). 'Developmental Systems and Evolutionary Explanation.' Journal of Philosophy 91: 277-304.

Griffiths, P. E., and Gray, R. D. (1997). 'Replicator II: Judgment Day.' Biology and Philosophy 12: 471-92. 
Griffiths, P. E., and Gray, R. D. (2005). 'Three Ways to Misunderstand Developmental Systems Theory.' Biology and Philosophy 20: 417-25.

Griffiths, P. E., and Machery, E. (2008). 'Innateness, Canalisation, and "Biologicizing the Mind".' Philosophical Psychology 21: 397-414.

Griffiths, P. E., Machery, E., and Linquist, S. (2009). 'The Vernacular Concept of Innateness.' Mind and Language 24: 605-30.

Griffiths, P. E., and Stotz, K. (2013). Genetics and Philosophy: An Introduction. New York: Cambridge University Press.

Griffiths, P. E., and Stotz, K. (forthcoming). 'How DST Became a Process Theory.' In D. J. Nicholson and J. Dupré (eds), Everything Flows: Towards a Processual Philosophy of Biology. Oxford: Oxford University Press.

Griffiths, P. E., and Tabery, J. G. (2013). 'Developmental Systems Theory: What Does It Explain, and How Does It Explain It?’ In R. M. Lerner and J. B. Benson (eds), Embodiment and Epigenesis: Theoretical and Methodological Issues in Understanding the Role of Biology within the Relational Developmental System, Part A: Philosophical, Theoretical, and Biological Dimensions, 65-94. New York: Academic Press.

Gros-Louis, J., West, M. J., and King, A. P. (2014). 'Maternal Responsiveness and the Development of Directed Vocalizing in Social Interactions.' Infancy 19: 385-408.

Gros-Louis, J., West, M. J., and King, A. P. (2016). 'The Influence of Interactive Context on Prelinguistic Vocalizations and Maternal Responses.' Language Learning and Development 12: 280-94.

Hinde, R. A. (1968). 'Dichotomies in the Study of Development.' In J. M. Thoday and A. S. Parkes (eds), Genetic and Environmental Influences on Behaviour, 3-14. New York: Plenum. 
Hull, D. L. (1986). 'On Human Nature.' Proceedings of the Philosophy of Science Association 1: 3-13.

Jayaratne, T. E., Gelman, S. A., Feldbaum, M., Sheldon, J. P., Petty, E. M., and Kardia, S. L. R. (2009). 'The Perennial Debate: Nature, Nurture, or Choice? Black and White Americans' Explanations for Individual Differences.' Review of General Psychology 13: $24-33$.

Kronfeldner, M., Roughley, N., and Toepfer, G. (2014). 'Recent Work on Human Nature: Beyond Traditional Essences.' Philosophy Compass 9: 642-52.

Laland, K. N., Odling-Smee, F. J., and Feldman M. W. (2000). 'Niche Construction, Biological Evolution, and Cultural Change.' Behavioral and Brain Sciences 23: 131-57. Lehrman, Daniel S. (1953). 'Critique of Konrad Lorenz's Theory of Instinctive Behavior.' Quarterly Review of Biology 28: 337-63.

Lewens, T. (2012a). 'Human Nature: The Very Idea.' Philosophy and Technology 25: 45974.

Linquist, S., Machery, E., Griffiths, P. E., and Stotz K. (2011). 'Exploring the Folkbiological Conception of Human Nature.' Philosophical Transactions of the Royal Society B 366: 444-53.

Machery, E. (2008). ‘A Plea for Human Nature.' Philosophical Psychology 21: 321-9.

Mameli, M., and P. P. G. Bateson (2006). 'Innateness and the Sciences.' Biology and Philosophy 21: 155-88.

Mameli, M., and P. Bateson. (2011). 'An Evaluation of the Concept of Innateness.' Philosophical Transactions of the Royal Society of London B 366: 436-43.

Medin, D. L., and Atran, S. (1999). 'Introduction.' In Medin and Atran (eds), Folkbiology, 1-15. Cambridge, Mass.: MIT Press. 
Medin, D., and Atran, S. (2004). 'The Native Mind: Biological Categorization and Reasoning in Development and Across Cultures.' Psychological Review 111: 960-83.

Medin, D., and Ortony, A. (1989). 'Psychological Essentialism.' In S. Vosniadou and A. Ortony (eds), Similarity and Anological Reasoning, 175-95. Cambridge: Cambridge University Press.

Mitchell, S. D. (2003). Biological Complexity and Integrative Pluralism. Cambridge: Cambridge University Press.

Mitchell, S. D. (2009). Unsimple Truths: Science, Complexity, and Policy. Chicago: University of Chicago Press.

Narvaez, D., Gleason, T., Wang, L. J., and Brooks, J. (2013). 'The Evolved Development Niche: Longitudinal Effects of Caregiving Practices on Early Childhood Psychosocial Development.' Early Childhood Research Quarterly 28: 759-73.

Oyama, S. (2000). Evolution's Eye: A Systems View of the Biology-Culture Divide. Durham, NC: Duke University Press.

Parrott, R., and Smith, R. A. (2014). 'Defining Genes Using "Blueprint” versus "Instruction" Metaphors: Effects for Genetic Determinism, Response Efficacy, and Perceived Control.' Health Communication 29: 137-46.

Ramsey, G. (2012). 'How Human Nature Can Inform Human Enhancement: A Commentary on Tim Lewens’s "Human Nature: The Very Idea".' Philosophy and Technology 25: 479-83. doi: 10.1007/s13347-012-0087-2.

Ramsey, G. (2013). 'Human Nature in a Post-Essentialist World.' Philosophy of Science 80: 983-93.

Sterelny, K. (2003). Thought in a Hostile World: The Evolution of Human Cognition. Oxford: Blackwell.

Sterelny, K. (2012). The Evolved Apprentice, Cambridge, Mass.: MIT Press. 
Sterelny, K., and Griffiths, P. E. (1999). Sex and Death: An Introduction to the Philosophy of Biology. Chicago: University of Chicago Press.

Stotz, K. (2010). 'Human Nature and Cognitive-Developmental Niche Construction.' Phenomenology and the Cognitive Sciences 9: 483-501.

Stotz, K. (2014). 'Extended Evolutionary Psychology: The Importance of Transgenerational Developmental Plasticity.' Frontiers in Psychology 5: doi: 10.3389/fpsyg.2014.00908.

Stotz, K. (2017). 'Why Developmental Niche Construction Is Not Selective Niche Construction - and Why It Matters.' Interface Focus, 7: 2-10.

Stotz, K., and Allen, C. (2012). 'From Cell-Surface Receptors to Higher Learning: A Whole World of Experience.' In K. Plaisance and T. Reydon (eds), Philosophy of Behavioural Biology, 85-123. Boston, Mass.: Springer.

Stotz, K., and Griffiths, P. E. (2008). 'Biohumanities: Rethinking the Relationship between Biosciences, Philosophy and History of Science, and Society.' Quarterly Review of Biology 83: 37-45.

Stotz, K., and Griffiths, P. E. (2016). 'A Niche for the Genome.' Biology and Philosophy 31: $143-57$.

Sultan, S. E. (2015). Organism and Environment: Ecological Development, Niche Construction, and Adaptation. Oxford: Oxford University Press.

Trevathan, W. (2011). Human Birth: An Evolutionary Perspective. New York: Aldine de Gruyter.

Waddington, C. H. (1942). 'Canalisation of Development and the Inheritance of Acquired Characters.' Nature 150: 563-5.

West, M. J., and King, A. P. (1987). 'Settling Nature and Nurture into an Ontogenetic Niche.' Developmental Psychobiology 20: 549-62. 
West, M. J., and King, A. P. (2008). 'Deconstructing Innate Illusions: Reflections on Nature-Nurture-Niche from an Unlikely Source.' Philosophical Psychology 21: 383-95.

Table 3.1

Comparison between the genetic essentialism framework (GEF) and the three-factor model

\section{Genetic essentialist elements}

\section{(Dar-Nimrod and Heine 2011a)}

Immutable and determined: thinking about genetic attributions leads people to view relevant phenotypes as less changeable and predetermined

Specific etiology: the tendency to discount additional causal explanations once genetic attributions are made

Homogeneous and discrete: leads to a focus on the central identifying features that are common to all group members, drawing attention away from in-group differentiating features

Nature: phenotypes are perceived as a natural outcome (with positive normative

\section{Three-factor model of animal natures}

\section{(Linquist et al. 2011)}

Fixity: phenotypes that are part of an animal's nature do not depend on the particular environment in which the organism is raised and are hard to change by environmental manipulations

Traits are either expression of the animal's nature (and are expected to have the three features) or imposed by the environment (with opposite expectations)

Typicality: phenotypes that are part of an animal's nature are typical of the entire species or of some natural subset such as males or juveniles

Teleology: phenotypes that are part of an animal's nature serve some purpose (with 
associations)

positive normative associations) 